\title{
Introducing Web 2.0: weblogs and podcasting for health librarians
}

\author{
Eugene Barsky
}

Discussion is rampant amongst libraries and information industries about what is Web 2.0. One thing, I believe, is clear now; Web 2.0 isn't a standard in almost any sense of the word. Most concepts behind this term are constructive, building on today's best and improving for the future. Stephen Abram suggested in his recent Information Outlook article that Web 2.0 is about the more human aspects of interactivity on the Web: "It is about conversations, interpersonal networking, personalization and individualism" [1]. Frequently, our users want to experience the Web; they want to learn and succeed. And we have to provide the tools and context so they can do just that. As the technology infrastructure of Web 2.0 is still complex and constantly evolving, Web 2.0 is ultimately a social phenomenon of users' experience of the Web and is characterized by open communication, decentralization of authority, and freedom to share and re-use Web content.

Many new technologies are emerging under the Web 2.0 umbrella: really simple syndication (RSS), wikis, weblogs, comments functionality, Web personalization, photo sharing (Flickr, Zooomr), social networking software, AJAX and API programming (Google maps), streaming media, podcasting and MP3 files, social bookmarking, open source software, user driven ratings, and open access content. My intent is to discuss some of these technologies and to see how we, as health sciences librarians and medical librarians, can integrate them into our daily practice. I started this series of articles by covering RSS use in medicine [2]. In this installment I am discussing weblogging and podcasting. If you are interested, please see my coverage of social networking and social bookmarking and tagging in the next issue of the Journal of the Canadian Health Libraries Association.

\section{Weblogs}

Before 1997, the term weblog just didn't exist. By 1999, there were only a few hundred weblogs. Today, the search site Technorati.com tracks almost 29 million of them. Weblogs, or blogs, have been defined as online journals, published chronologically, with links to and commentary on various issues of interest. Blogs are easy to create and publish for many reasons. First, one does not need to know

E. Barsky. Irving K. Barber Learning Centre, University of British Columbia, 1961 East Mall, Vancouver, BC V6T 1Z1, Canada (e-mail: eugene.barsky@ubc.ca, blog: http://weblogs.elearning.ubc.ca/physio/).
HTML coding to create a Web page. The software will do that for you as they all have built-in templates. Second, the weblog writer does not have to arrange any space on a server as most weblog tools provide free hosting space. The only work that the weblog writer needs to accomplish is creating the text. It's that simple. This ease of online publishing has made weblogs an international phenomenon, and numerous librarians and library workers have created them in recent years. Frequently, blogs are networked between several people, and several members post thoughts that often revolve around a common theme.

A January 2005 Pew Internet and American Life Project memo, "The State of Blogging", found that $27 \%$ of Internet users said they read blogs - a $58 \%$ increase from the previous survey in early 2004 (www.pewinternet.org/pdfs/ PIP_blogging_data.pdf). So, yes, this is a widespread and popular Web trend. Many medical librarians have already jumped on this Web bandwagon. Some of these blogs (which I read) include Michelle Kraft's The Krafty Librarian (http://www.kraftylibrarian. blogspot.com/), Dean Giustini's UBC Google Scholar Blog (http://weblogs.elearning.ubc.ca/ googlescholar/), and Denise Koufogiannakis' Librarians' Rx (http://www.library.ualberta.ca/mt/blog/librariansrx/).

Other library blogs that I subscribe to include Gary Price's excellent ResourceShelf (http://www.resourceshelf.com/) and Jenny Levine's The Shifted Librarian (http://www. theshiftedlibrarian.com/). For some entertainment (we all have a life too, no?), I like reading my RSS feed from BoingBoing (http://www.boingboing.net/).

Those of us who haven't started a weblog, but are considering doing so, can get started right away (yes, right after finishing this article!). While there are many weblog software tools available, users may want to try Google's Blogger (www.blogger.com), MoveableType (www.movabletype.org), or Live Journal (www.livejournal.com) to get started. All these publishing tools are easy to use and cost nothing (or next to it), and they can have a weblog up and running in a matter of minutes.

It will take you about $10 \mathrm{~min}$ to start your first blog by going through the simple steps at Blogger (www.blogger.com). After deciding on a username and password, you title your blog and choose a template (which can be changed anytime) for your page. You will also create a profile; it is how others will find you (and also how you locate people with similar interests).

Admittedly, blogging is not for everybody; think about 
content that you are willing to share. It is a good idea to stay on point; if you maintain a library blog, it should reflect the professional standards you apply to every other publishing venue. The content you track should be distinctive, the sort of material that no one else could present more effectively than you. A lively discussion and presentation help to define a sense of community and identity.

You want to search for other people's posts on their blogs? Here are two of the more robust (in my modest opinion) search engines that specialize in indexing weblogs:

(1) Technorati (http://www.technorati.com/) - This is one of the biggies, and it is able to search for almost 29 million blogs. One of the handy features is searching for blogs by subject. For example, a search for dermatology blogs retrieves only six hits (http://www.technorati.com/blogs/ dermatology).

(2) Google Blog Search (http://blogsearch.google.com/) This is a powerful search engine for self-publishing weblogging content. The good thing is that many of the standard Google control language commands are supported. For instance, you can search blogs by author (inpostauthor:) or by words in the title (inblogtitle:).

Definitely, I agree, not everyone is born to blog, but blogging deserves a close look, not only because of its simplicity, but also because of its potential to open a new zone for professional practice and communication channels, particularly in public and academic librarianship.

\section{Podcasting}

In January and February 2005, the Pew Internet and American Life Project conducted a survey of iPod and MP3 player users. It learned that more than 22 million of those who are age 18 and older own an iPod or MP3 player (http://www.pewinternet.org/PPF/r/154/report_display.asp).

Podcast, defined in the New Oxford American Dictionary as "a digital recording of a radio broadcast or similar program, made available on the Internet for downloading to a personal audio player", is the 2005 Word of the Year, according to the dictionary editors [3]. Podcasts are basically digital files you can download from the Web and listen to whenever and wherever you want. Free (or very inexpensive) software makes it easy for computer users to subscribe to regular podcast feeds, download them automatically, and transfer them to a portable device like an iPod for later playback. Created by ordinary people, podcasts use RSS technology and can also be described as audio RSS feeds. Because they are feeds, users can subscribe to podcasts and have them downloaded automatically to their computers, just as news aggregators automatically capture RSS feeds.

Surely, to receive or download podcasts you do not need an iPod; you can use any MP3 player. You can also listen to podcasts on any laptop or desktop computer equipped with speakers and supported by media software such as Windows Media Player or Real Networks RealOne Player. Also, you can listen to podcasts on your Palm Pilot or cell phone. Many podcast programs are quite short, so they are perfect for my 30-45 min daily commute (public transport is not bad in Vancouver).

Could I recommend any reliable medical podcasts to try? Michelle Kraft (The Krafty Librarian) has recently compiled an impressive list of various health-related podcasts (http://www.kraftweb.net/kl/podcasts.doc) that includes my favorites: The Naked Scientists (http://www.thenakedscientists. com/HTML/Shows/streaming_media.htm) (listen to their "Why chocolate is good for you" - good news for all chocoholics out there), and the Nature Publishing Group podcasts (http://www. nature.com/nature/podcast/index.html).

Now, for those of you working in the academic environment, what do think about coursecasting? Drexel University, which distributed iPods to students in its School of Education last fall, has already started experimenting with podcasting, as has Duke University, which last year handed out iPods to every incoming freshman. Governments also do not want to miss the trend. Very recently, the US government has started to supply podcasts on different subjects of interest (http://www. firstgov.gov/Topics/Reference_Shelf/Libraries/Podcasts.shtml), including a health section from the Agency for Healthcare Research and Quality. Personally, I believe that the Canadian government is soon to catch the wave.

Interested in producing some podcasts? Here is my insight regarding podcasting. First of all, you have to know your audience and select focused topics. Remember, the content is very important; substance trumps style. You also have to be lively and genuine; scripted discourse is hard on the ears. And please keep it short because long audio files will test your users' patience.

If you are interested in searching for podcasting content, take a look at the following specialized search engines:

(i) Yahoo podcast search (http://podcasts.yahoo.com/) This is an excellent and powerful search engine (still in beta) that will allow you to listen to, search for, and subscribe to the audio content distributed on the Web.

(ii) Podscope (http://www.podscope.com/) from TVEyes (http://www.tveyes.com/) - This is one of the first engines to allow searchers to keyword search podcasts and then go directly to where the words were spoken in the program (transcript search). A nice feature also allows you to subscribe to a podcast RSS feed for your search terms.

The iPod continues to shrink in both size and price with the debut of the iPod Shuffle, but its "cool" factor is still growing. Podcasting is really big now, but what will it be like 1 year, 5 years, or 10 years from now?

Even though podcasting is still in a very early stage, I expect it to continue to grow in popularity as it receives more mainstream press, develops new tools (for the creation of content and the delivery of content to the end user), and increases public awareness that iPods or other MP3 players can hold not just MP3 files but other types of content (e.g., pictures, video, text). What kind of audio or video content will your library users want to take with them? The podcasting phenomena will grow in ways that we haven't even envisioned yet. This is definitely another exciting trend to watch.

\section{References}

1. Abram S. Web 2.0 - Huh?! Library 2.0, Librarian 2.0. Information Outlook. 2005;9(12):44-5.

2. Barsky E. Introducing Web 2.0: RSS trends for health librarians. J Can Health Libr Assoc. 2006;27(1):7-8.

3. McKean E, editor. New Oxford American Dictionary. 2nd ed. New York: Oxford University Press; 2005. 
This article has been cited by:

1. Eugene Barsky, Dean Giustini. 2007. Introducing Web 2.0: wikis for health librarians. Journal of the Canadian Health Libraries Association 28:4, 147-150. [Abstract] [PDF] [PDF Plus]

2. Eugene Barsky, Allan Cho. 2007. Introducing Web 2.0: social search for health librarians. Journal of the Canadian Health Libraries Association 28:2, 59-61. [Abstract] [PDF] [PDF Plus]

3. Allan Cho. 2007. An introduction to mashups for health librarians. Journal of the Canadian Health Libraries Association 28:1, 19-22. [Citation] [PDF] [PDF Plus]

4. Eugene Barsky, Michelle Purdon. 2006. Introducing Web 2.0: social networking and social bookmarking for health librarians. Journal of the Canadian Health Libraries Association 27:3, 65-67. [Citation] [PDF] [PDF Plus] 